\title{
Coleção fluídica na interface do LASIK causada por glaucoma secundário à ceratouveíte herpética: relato de caso
}

\author{
LASIK interface fluid accumulation caused by glaucoma associated with \\ herpetickeratouveitis:case report
}

\author{
Eliane Mayumi Nakano ${ }^{1}$ \\ Márcio Kuchembuck ${ }^{2}$ \\ KozoNakano ${ }^{3}$ \\ Marivaldo Oliveira ${ }^{4}$ \\ Lenio Souza Alvareng'a ${ }^{5}$ \\ Waldir Portellinha ${ }^{6}$
}

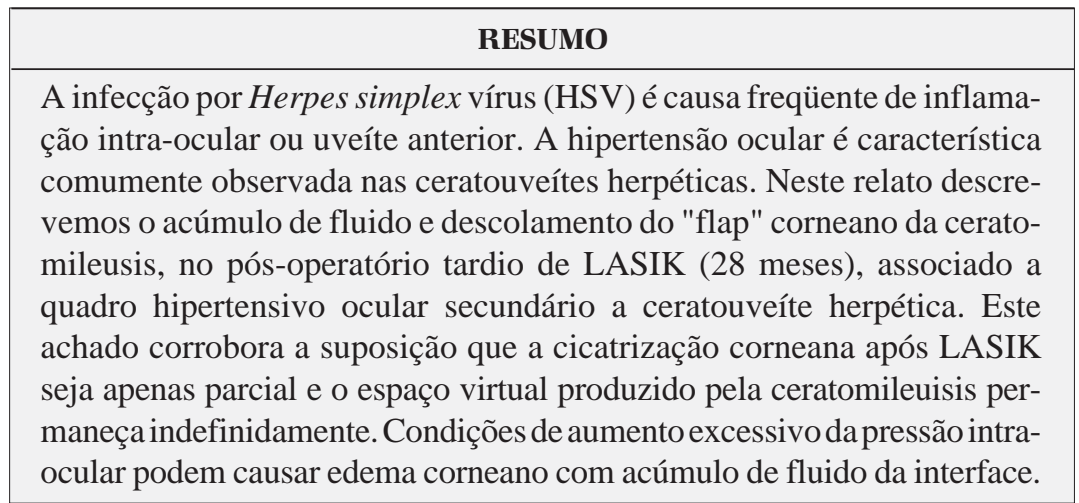

Descritores: Herpes simples; Uveíte; Glaucoma; Ceratomileuse assistida por excimer laser in situ; Complicações pós-operatórias [tipo de publicação]

\section{INTRODUÇ̃̃OO}

Descrições na literatura apontam que a infecção por Herpes simplex vírus (HSV) é a causa mais freqüentemente associada a inflamação intraocular ou uveíte anterior em outros países ${ }^{(1-3)}$. Acredita-se que o HSV tipo 1 seja responsável pelo aparecimento do quadro de iridociclite, enquanto o HSV tipo 2 é observado nos casos de necrose aguda de retina $(\mathrm{ARN})^{(4)}$. Entretanto, o diagnóstico de uveíte herpética por vezes não é feito pelo fato de a ceratite poder não acompanhar o quadro de uveíte anterior e atrofia setorial de íris ${ }^{(1)}$.

O quadro clínico da ceratouveíte, desta forma, conta com ceratite dendrítica, infiltrados corneanos em estroma profundo, precipitados ceráticos não granulomatosos e reação de câmara anterior. Sinéquias, hifema e hipópio também podem estar presentes ${ }^{(5-6)}$.

A uveíte herpética se caracteriza pela recorrência, tendo sido este fato postulado como característica patognomônica da doença ${ }^{(7)}$. Acredita-se que fatores desencadeadores das recorrências estejam associados a estados imunológicos do portador, embora já tenham sido descrito casos de recorrência da ceratouveíte após iridotomia com argon e yag laser ${ }^{(8-9)}$.

O aumento da pressão intra-ocular é outro ponto importante e comumente observado nas ceratouveítes herpéticas, sendo estas então, a causa mais comum de glaucoma secundário a uveítes ${ }^{(5,10-14)}$.

Durante o acompanhamento pós-operatório de um caso de ceratomileuse assistida por excimer laser in situ (LASIK), notou-se uma inflamação 
ocular com acúmulo de fluido na interface e descolamento do "flap" da ceratomileusis. O paciente referia episódio prévio de ceratouveíte herpética.

\section{RELATO DO CASO}

Paciente do sexo masculino, 46 anos, apresentava exame biomicroscópico normal em ambos os olhos, com pressão intra-ocular (Goldman) de $12 \mathrm{mmHg}$ em ambos os olhos. Referia episódio prévio de ceratite herpética havia quatro anos, tendo sido tratado com aciclovir tópico sem intercorrências. Apresentava refração pré-operatória: $\mathrm{OD}:+2,75 \mathrm{DE}=-0,75 \mathrm{DC}$ a 95 e OE: + 4,00DE. Foi submetido a LASIK em ambos os olhos sem intercorrências. No pós-operatório apresentou visão sem correção de 20/20 em ambos os olhos.

Após dois anos e quatro meses da cirurgia, o paciente retornou com história de dor ocular, hiperemia intensa, fotofobia no olho direito por dois dias. Ao exame apresentava OD com acuidade (com a melhor correção) de 20/200. À biomicroscopia se evidenciavam hiperemia ciliar, reação de câmara anterior, precipitados ceráticos (Figura 1). Ainda, edema intenso de córnea e delaminação do estroma corneano no nível da ceratomileusis, sendo possível observar acúmulo de fluido na interface (Figura 2).

A medida da pressão intra-ocular através de digitopressão acusava um aumento importante. A medida de tonometria de aplanação foi ignorada uma vez que se mostrava falsamente baixa decorrente ao edema de córnea. Considerou-se o quadro clínico compatível com o diagnóstico de ceratouveíte herpética, instituindo-se o tratamento com aciclovir oral $2 \mathrm{~g}$ ao dia, prednisona $60 \mathrm{mg}$ oral ao dia, colírios tópicos de acetato de prednisolona $1 \%$, tropicamida $1 \%$ a cada 6 horas e maleato de timolol $0,5 \%$ a cada 12 horas. O corticosteróide oral e tópico foi diminuído gradualmente. Após três semanas o paciente apresentava Acuidade visual de 20/20 com correção no olho acometido, PIO de $12 \mathrm{mmHg}$, e sem alterações à biomicroscopia.

\section{DISCUSS ÃO}

As complicações pós-operatórias não-refracionais do LASIK usualmente estão relacionadas à interface. A presença desta no pós-operatório cria um microambiente que pode propiciar a proliferação de grupos especiais de bactérias (e.g. micobactérias atípicas $)^{(15)}$. O seqüestro de substâncias tóxicas nesta região pode levar à inflamação pós-operatória (e.g. ceratite lamelar difusa, reação a corpo estranho) ${ }^{(16)}$ e comprometimento da visão.

Exames de microscopia confocal mostram alterações da morfologia e arquitetura intercelular na interface do flap, o que sugere que a ceratomileusis na cirurgia de LASIK produz um espaço virtual permanente a esta profundidade do estroma corneano $^{(17)}$. Tal fato também foi evidenciado por relatos de levantamento do flap da ceratomileusis após 18 meses da cirurgia para reaplicação do excimer laser ${ }^{(18)}$. Desta forma, o espaço virtual da interface pode ser distendido durante a formação do edema de córnea.

A presença indefinida da interface como uma área de fragilidade corneana tem sido citada como um dos fatores a serem considerados na escolha do tratamento refrativo corneano a laser. A área de fragilidade no estroma levaria a manifestações diferentes das doenças corneanas, especialmente o acúmulo de fluido na interface. É importante reconhecer estas manifestações atípicas para se fazer o correto diagnóstico e tratamento. $\mathrm{O}$ deslocamento tardio de flap durante trauma acidental ${ }^{(19-21)}$ ou mesmo cirúrgico ${ }^{(22)}$ também é uma preocupação decorrente desta área de fragilidade corneana.

Relatos de acúmulo de fluido e descolamento do flap foram previamente descritos na literatura ${ }^{(23-25)}$. O mecanismo proposto para tal condição é o aumento da pressão intra-ocular causando o edema do tecido corneano, culminando na coleção líquida na interface ${ }^{(23,26)}$. Nestes casos é bem estabelecido que a pressão intra-ocular medida por aplanação sobre a re-

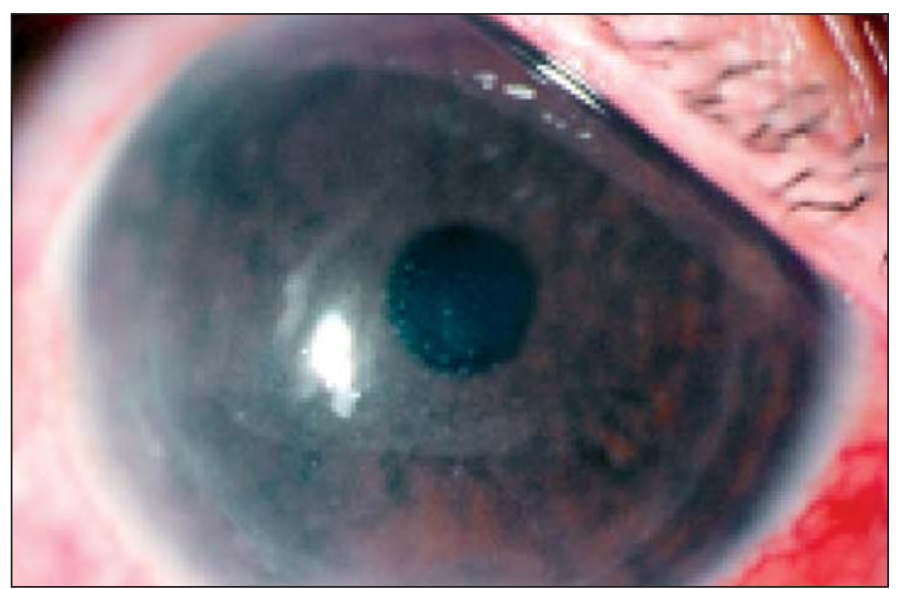

Figura 1 - Nota-se hiperemia conjuntival, com reação de câmara anterior e precipitados ceráticos

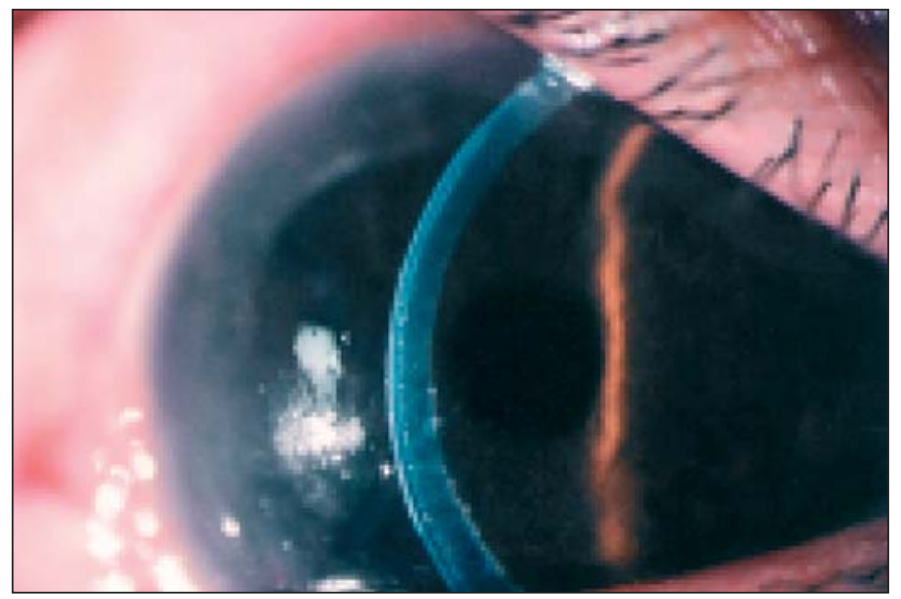

Figura 2 - O acúmulo de líquido no espaço virtual provocado pela ceratomileusis ocasiona uma delaminação da córnea, que é bem nítida ao exame em fenda. 
gião do flap estará subestimada e isso deve ser considerado no manejo do paciente (e.g. utilizar avaliação bidigital ou tonopen na periferia da córnea).

A possibilidade do trauma cirúrgico da cirurgia refrativa servir como estímulo à reativação de infecção latente por herpes vírus já foi comprovada em modelos animais ${ }^{(27)}$. Esta associação, entretanto, ainda não foi estudada em coortes prospectivas o que dificulta a identificação e quantificação deste possível risco. Apesar de relato na literatura sugerindo uma correlação entre a cirurgia refrativa e a reativação da infecção herpética dois anos ${ }^{(28)}$ após o procedimento, consideramos que a alta latência torna improvável uma associação direta.

No caso descrito identificamos que sob condições de aumento excessivo da pressão intra-ocular e conseqüente edema corneano ocorreu acúmulo de fluido na interface do LASIK, 28 meses após a confecção do flap. No nosso paciente houve regressão total sem seqüela visual após o controle da hipertensão ocular.

\section{ABSTRACT}

Herpes simplex virus infection is a frequent cause of intraocular inflammation or anterior uveitis. Ocular hypertension is a common feature in herpetic keratouveitis. We describe a fluid accumulation and flap displacement in late postoperative period (28 months) of LASIK associated with ocular hypertension caused by herpetic keratouveitis. This finding supports the theory that flap attachment after LASIK is only partial and the virtual space remains indefinitely. The presence of ocular hypertension may lead to corneal edema and fluid accumulation in the interface.

Keywords: Herpes simplex; Uveitis; Glaucoma; Keratomileusis, laser in situ; Postoperative complications [type publication]

\section{REFERÊNCIAS}

1. Santos C. Herpes simplex uveitis. Bol Asoc Med P R. 2004;96(2):71-4,77-83.

2. Islam SM, Tabbara KF. Causes of uveitis at The Eye Center in Saudi Arabia: a retrospective review. Ophthalmic Epidemiol. 2002;9(4):239-49.

3. Gaynor BD, Margolis TP, Cunningham ET Jr. Advances in diagnosis and management of herpetic uveitis. Int Ophthalmol Clin. 2000;40(2):85-109.

4. Usui N, Kashiwase M, Minoda H, Yamauchi Y, Sakai J, Usui M, et al. [Typing of herpes simplex virus in patients with uveitis]. Nippon Ganka Gakkai Zasshi. 2000;104(7):476-82. Japanese.
5. Baltatzis S, Romero-Rangel T, Foster CS. Sectorial keratitis and uveitis: differential diagnosis. Graefes Arch Clin Exp Ophthalmol. 2003;241(1):2-7.

6. Nussemblatt RB, Whitcup SM, Palestine AG. Uveitis: fundamentals and clinical practice. 2nd ed. Philadelphia: Mosby; 1996. p.207-10.

7. Garweg JG. [Clinical manifestations of herpetic keratitis and uveitis] Ther Umsch. 2001 Jan;58(1):13-20. German.

8. Gaynor BD, Stamper RL, Cunningham ET Jr. Presumed activation of herpetic keratouveitis after Argon laser peripheral iridotomy. Am J Ophthalmol. 2000;130(5):665-7.

9. Hou YC, Chen CC, Wang IJ, Hu FR. Recurrent herpetic keratouveitis following YAG laser peripheral iridotomy. Cornea. 2004;23(6):641-2.

10. Takahashi T, Ohtani S, Miyata K, Miyata N, Shirato S, Mochizuki M. A clinical evaluation of uveitis-associated secondary glaucoma. Jpn J Ophthalmol. 2002;46(5):556-62

11. Fong Choong Y, Austin MW. Secondary glaucoma associated with anterior uveitis, iris pigment epithelitis and herpetic eye infection. Acta Ophthalmol Scand. 2002;80(6):672-4

12. Takahashi T, Ohtani S, Miyata K, Miyata N, Shirato S, Mochizuki M. A clinical evaluation of uveitis-associated secondary glaucoma. Jpn J Ophthalmol. 2002;46(5):556-62.

13. Saouli N, Brezin AP. [Ocular hypertension and uveitis. Study of 374 cases of uveitis]. J Fr Ophtalmol. 1999;22(9):943-9. French.

14. Merayo-Lloves J, Power WJ, Rodriguez A, Pedroza-Seres M, Foster CS. Secondary glaucoma in patients with uveitis. Ophthalmologica. 1999;213(5):300-4.

15. Alvarenga L, Freitas D, Hofling-Lima AL, Belfort R Jr, Sampaio J, Sousa L, et al. Infectious post-LASIK crystalline keratopathy caused by nontuberculous mycobacteria. Cornea. 2002;21(4):426-9.

16. Stulting RD, Randleman JB, Couser JM, Thompson KP. The epidemiology of diffuse lamellar keratitis. Cornea. 2004;23(7):680-8.

17. Dawson DG, Edelhauser HF, Grossniklaus HE. Long-term histopathologic findings in human corneal wounds after refractive surgical procedures. Am J Ophthalmol. 2005;139(1):168-78.

18. Netto MV, Wilson SE. Flap lift for LASIK retreatment in eyes with myopia. Ophthalmology. 2004;111(7):1362-7.

19. Franklin QJ, Tanzer DJ. Late traumatic flap displacement after laser in situ keratomileusis. Mil Med. 2004;169(4):334-6.

20. Srinivasan M, Prasad S, Prajna NV. Late dislocation of LASIK flap following fingernail injury. Indian J Ophthalmol. 2004;52(4):327-8.

21. Tumbocon JA, Paul R, Slomovic A, Rootman DS. Late traumatic displacement of laser in situ keratomileusis flaps. Cornea. 2003;22(1):66-9.

22. Jonas JB. Displacement of a laser in situ keratomileusis flap during retinal detachment surgery. Acta Ophthalmol Scand. 2004;82(3 Pt 1):314-5.

23. Portellinha W, Kuchenbuk M, Nakano K, Oliveira M. Interface fluid and diffuse corneal edema after laser in situ keratomileusis. J Refract Surg. 2001;17(2 Suppl):S192-5.

24. Fraunfelder FW, Schena LB. Watch out: refractive surgery and drug side effects. EyeNet Magazine. 2004.

25. Fogla R, Rao SK, Padmanabhan P. Interface fluid after laser in situ keratomileusis. J Cataract Refract Surg. 2001;27(9):1526-8.

26. Bissen-Miyajima H, Nakamura K, Kaido M, Shimmura S, Tsubota K. Role of the endothelial pump in flap adhesion after laser in situ keratomileusis. J Cataract Refract Surg. 2004;30(9):1989-92.

27. Dhaliwal DK, Romanowski EG, Yates KA, Hu D, Goldstein M, Gordon YJ Experimental laser-assisted in situ keratomileusis induces the reactivation of latent herpes simplex virus. Am J Ophthalmol. 2001;131(4):506-7.

28. Levy J, Lapid-Gortzak R, Klemperer I, Lifshitz T. Herpes simplex virus keratitis after laser in situ keratomileusis. J Refract Surg. 2005;21(4):400-2.
Ao enviar um artigo para publicação, leia ATENTAMENTE as instruções para autores, constante no final de cada fascículo. 